\title{
THEORETICAL FRAMEWORKS FOR ACADEMIC DISHONESTY
}

\author{
A COMPARATIVE REVIEW
}

Michele DiPietro, Carnegie Mellon University

Academic dishonesty has so far been understood using theoretical frameworks derived from criminology literature. These frameworks contribute pieces of the puzzle and even enjoy some empirical support, but conceptualizing students as delinquents is problematic and ultimately ineffective. This chapter reviews the current frameworks, including their theoretical underpinnings, empirical support, and strategies they suggest, and goes on to analyze their limitations and suggest alternative frameworks.

Since the landmark study of Bowers (1964), where 75 percent of five thousand students at ninety-nine colleges and universities admitted to cheating at least once, the figures have not changed much. More recent estimates range from 70 percent to 80 percent, with a peak of 95 percent of students admitting to cheating (Brown \& Emmett, 2001; McCabe \& Trevino, 1993; Stern \& Havlicek, 1986; Whitley, 1998). Faculty, educational developers, student affairs professionals, and higher education researchers have all devoted effort, resources, and programs to reduce cheating, but given these figures, the return on investment of such initiatives is disheartening.

This chapter explores possible reasons for this disconnect. To understand the limitations of current approaches, it is helpful for faculty developers to understand the theoretical frameworks that have been used to explain academic dishonesty and their origination. This chapter is divided into three sections. The first section reviews the theoretical frameworks scholars currently use to conceptualize academic integrity and the research supporting them, as well as their fundamental limitations. The second section proposes alternative ways to think about cheating, and the last section addresses the implications for educational development. 


\section{Current Frameworks}

In my review of the literature on cheating and academic integrity, five theoretical frameworks are the most common: (1) deterrence theory, (2) rational choice theory, (3) neutralization theory, (4) planned behavior theory, and (5) situational ethics. Before I describe them, some caveats are in order.

First, as in every field that investigates stigmatized behavior, research subjects will understate their participation in such behaviors or deny them altogether. Although it is possible to employ research techniques that reduce such positive response bias, it is generally not possible to eliminate it altogether. Second, studies of cheating may not be directly comparable. The researcher can avoid positive response bias by not asking about cheating directly. Some studies ask about cheating behaviors observed in peers, while others ask about hypothetical scenarios ("Given this situation, would you engage in this behavior?"). Still others set up experimental situations where the researchers themselves can observe cheating. Diversity of methods yields diversity of results, creating a problem for comparability across research studies. I have relied heavily on Whitley's meta-analysis (1998) of 107 studies of the correlates of cheating and effect size measures for each correlate to obviate the problem of comparing studies conducted using different methods. The results of his meta-analysis are more compelling than the results of each individual study. I use his estimates as measures of support of the theoretical frameworks I consider.

Finally, and most important, the theoretical perspectives that have informed research on academic dishonesty thus far all share a common bias: they are all derived from theories of criminal behavior. Although some people may philosophically disagree with conceptualizing students as delinquents, this bias also creates a pragmatic problem. Criminal theories are theories of deviant behavior, designed to explain why a few individuals deviate from behavior that the rest of the population observes as normative and ethical. When more than 70 percent of students admit to having cheated, it is not clear who is deviant and who is in the norm anymore, and these theories lose much of their descriptive and predictive power.

\section{Deterrence Theory}

The deterrence theory posits that cheating is a function of the severity of the consequences (Zimring \& Hawkins, 1973). If we want to curtail a certain behavior, we should punish it with consequences severe enough to discourage students, including failing the assignment, failing the course, 
academic probation, or even expulsion. Research on the correlates of cheating behaviors partly supports the deterrence theory in that students' self-perception of their ability to cheat has a medium positive effect on cheating (Whitley, 1998). In other words, if students think they are able to engage in their behavior without consequences, they are likely to do so. Here and throughout this chapter, the strength of an effect (small, medium, and large) is calculated according to the rules for the $d$ statistic, a measure of effect size based on the standardized mean difference between cheaters and noncheaters on a given variable (Cohen, 1988).

The approach suggested by deterrence theory has some practical problems. Professors can dole out punishment with consequences only at the assignment and course level; therefore centralized academic review boards must lead in increasing the severity of the consequences. However, instructors are reluctant to report cases to their academic review board because of the extra effort involved (Schneider, 1999). Research also shows that the effectiveness and intensity of deterrents varies among cultures. For instance, Western students asked to list deterrents to cheating are very likely to mention expulsion as the ultimate deterrent. In Japan, students asked the same question are more likely than American students to focus on public humiliation-for example, making cheaters use only red ink pens to write for the rest of the year (Burns, Davis, \& Hoshino, 1998). Therefore, responses to academic dishonesty are not universal but should be tailored to the particular culture of the institution.

\section{Rational Choice Theory}

The rational choice theory treats dishonest actions as the result of decisions that rational agents make (Cornish \& Clarke, 1986). The eventual course of action is chosen after weighing the advantages and disadvantages of all possible alternatives. Therefore, deciding to cheat results from a cost-benefit analysis. The factors involved in the decision might include the effort involved in cheating rather than studying the material, the expected improvement in the grade due to cheating, the stakes involved in the assignment, and so on. Of course, the severity of the possible consequences also factors in, making the strategies suggested by deterrence theory, as well as its limitations, relevant to rational choice theory as well. Rational choice theory finds further support in the research on the correlates of cheating. The risk of being caught has a medium negative effect on cheating, the fear of punishment has a small negative effect, and the importance of the outcome has a medium positive effect (Whitley, 1998). 


\section{Neutralization Theory}

Other frameworks conceptualize students as moral beings as well as rational ones. Cost-benefit considerations aside, surely the effect of engaging in morally wrong acts should have psychological consequences on those who do so. In fact, earlier research on academic dishonesty focused on the so-called self-esteem cycle (Aronson \& Mettee, 1968; Ward, 1986). Cheaters were believed to start out with low-self esteem. They didn't think they would do well on the task, and they were not invested in maintaining a positive image with the instructor, because they didn't think he or she believed in their abilities. When they engaged in cheating, the knowledge of their morally wrong behavior further lowered their selfesteem, precipitating future iterations of this vicious cycle. This cycle unravels in view of the finding that, even though it is true that reported past cheating has a large positive effect on future cheating, it is not true that cheaters have low self-esteem (Whitley, 1998).

Neutralization theory (Sykes \& Matza, 1957), on the other hand, hypothesizes that students are able to engage in morally wrong acts without damage to their self-concept if they can rationalize those acts and think of them as morally neutral rather than wrong. Research on the correlates of cheating has found that neutralization techniques have a medium to large positive effect on cheating, thus lending support to this theory (Whitley, 1998). Out of the classic neutralization techniques used by delinquents, Storch, Storch, and Clark (2002) have identified four neutralization techniques used by college students:

1. Some cheaters might deny responsibility, saying they did nothing wrong or they didn't mean to and were influenced by circumstances beyond their control.

2. Others might deny consequences, claiming that cheating is no big deal or that it is a "victimless crime."

3. Still others might blame the authorities, saying it's the professor's fault if they have to cheat because the tests are always unfair, or professors too probably cheated as students.

4. Some might invoke a more compelling value system or higher loyalties that supersede academic rules, such as the value of helping friends pass the course.

This framework posits that efforts to prevent cheating should focus on deneutralizing it, perhaps emphasizing the consequences of various kinds of academic dishonesty (such as fabrication or falsification of data) to the 
scientific and intellectual community or stressing personal responsibility and agency.

\section{Planned Behavior Theory}

Planned behavior theory posits that cheating happens as a result of the opportunity as well as the intention to cheat (Ajzen, 1969). Therefore, efforts to prevent cheating should also act on both situational and behavioral factors. Instructors who reduce opportunities to cheat by being more vigilant during exams may only create frustrated cheaters who still have every intention to cheat at the next available opportunity. Proponents of planned behavior theory would focus their efforts both on prevention and on educating people about the value of academic integrity. Research on the correlates of cheating support both sides of the planned behavior theory. On the opportunity side, empty seats between students and multiple forms of the same test during exams have a medium and small negative effect on cheating, respectively. Conversely, letting students sit in the back of the room and letting them sit next to their friends have a small and medium positive effect on cheating, respectively. On the intention side, perception of a moral obligation to avoid cheating has a medium negative effect (Whitley, 1998).

\section{Situational Ethics}

Some people have raised the question of whether students cheat in response to extraordinary circumstances, where breaking the usual rules of ethical behavior is possibly justified. Consider the hypothetical situation of a student who needs to decide whether to help his foreign-born girlfriend cheat on an exam. He knows that she is on academic probation and that if she fails this test she will be expelled from the university, lose her student visa, and be deported back to her country, where her family will force her into an arranged marriage. He has a tough dilemma, and it is not clear which choice will lead to the best outcome. Situational ethics posits that such unique situations should be decided on the basis of a unique set of considerations that don't normally apply to other situations (Fletcher, 1966).

However, the situational ethics framework does not have empirical support. The high incidence of reported cheating suggests that students don't cheat in response to extreme-and therefore rare-circumstances, where breaches of academic integrity would possibly be understandable. In fact, reported past cheating has a large positive effect on cheating (Whitley, 1998). The premise that students use one set of ethical rules for most 
aspects of their life but suspend them in a few situations such as cheating is also undermined by findings; in their study of business students from six universities who worked a part-time or full-time job in the past five years, Nonis and Swift (2001) found a moderate to strong correlation between the frequency of academic dishonesty and the frequency of workplace dishonesty. The workplace dishonesty behaviors they considered included using office supplies for personal use, leaving early when the boss was absent, calling in sick when well, padding an expense report, or taking credit for someone else's work. Similar results hold for other populations, such as engineering students (Carpenter, Harding, \& Finelli, 2006).

\section{Limitations of Current Approaches and Need for New Ones}

The conceptual frameworks discussed so far and the empirical support they enjoy add to our understanding of cheating in higher education. Yet these theories have not given us tools to counteract cheating effectively. As mentioned previously, the reason these frameworks inevitably fall short is that they are actually theories of criminal behavior, with a less-than-perfect fit to academic situations.

That students do not conceptualize cheating as a criminal act is apparent from the research on perceptions of what constitutes cheating. Although most people agree on a few clear-cut situations (stealing a paper from a friend, fabricating research results, buying a paper from the Internet and submitting it as your own), gray areas and disagreement in perception exist not only between faculty and students but also among groups of faculty and groups of students. Different groups attribute varying degrees of seriousness to certain actions, such as submitting the same paper for two classes, referencing an article without having read it, paraphrasing words without attribution, or collaborating inappropriately (Higbee \& Thomas, 2002).

Cross-cultural research highlights even more discrepancies in perceptions of the seriousness of certain behaviors. In a study involving $\mathbf{8 8 5}$ students from the United States, Russia, the Netherlands, and Israel, Magnus, Polterovich, Danilov, and Savvateev (2002) presented a scenario in which "Student $C$ reports to the departmental office that student $A$, while taking an exam, copied answers from student $B$ 's paper with the consent of student B" (p. 126). The researchers asked the students to rate the behavior of all three characters. As expected, the ratings for student $A$ (the cheater) ranged from slightly negative to negative, those for student $B$ (the friend) ranged from negative to slightly positive, and those for 
student $C$ (the whistleblower) ranged from neutral to very negative. Neutralization techniques can explain the positive ratings for student $B$ and negative ratings for student $C$, where the former was rewarded for being a good friend and the latter was punished for not exhibiting solidarity. Interestingly, the U.S. average for student $\mathrm{C}$ was the only neutral rating; all other countries rated him negatively.

The high variability of judgment across students and instructors together with the high prevalence of cheating exposes the limitations of the current approaches to academic dishonesty and the need for alternative modes of conceptualizing cheating. We turn now to discussion of some possibilities.

\section{Cheating as Ignorance or Confusion About Instructor's Expectations}

Certain behaviors that instructors classify as cheating can actually stem from unarticulated expectations, especially those behaviors regarding plagiarism and collaboration. Misconceptions about plagiarism abound; for instance, many students think it is acceptable to quote without attribution if they do not use the actual language (Wilhoit, 1994). Collaboration policies have incredible variability across courses, from no collaboration allowed to collaboration encouraged, to rules such as the "Gilligan's Island collaboration policy" common in computer science departments (for an example, see Rutgers University, 2009). If this is the problem, instructors can easily obviate it by articulating and clarifying their expectations, policies, and the rationale behind them.

\section{Cheating as Learned Behavior}

By not explaining the value of academic integrity and not enforcing consequences for cheating, perhaps the environment in which students have been educated so far reinforces cheating and actually socializes them to do it. Given the prevalence of cheating, it is apparent that students do indeed grow up in a culture of cheating. Research on the correlates of cheating supports the learned behavior hypothesis because cheating norms on campus have a medium-to-large positive effect on the behavior (Whitley, 1998). If we subscribe to the learned behavior theory, then reducing cheating requires changing the campus culture.

The most effective known mechanism for changing the culture is introducing honor codes, which have a medium-to-large effect in reducing cheating (McCabe \& Trevino, 1993; McCabe, Trevino, \& Butterfield, 
1999; Whitley, 1998). Pure honor codes have four defining features (Melendez, 1985):

1. A written pledge to academic integrity that each student signs

2. Significant student involvement in academic review boards in charge of academic integrity violations

3. Unproctored exams

4. A clause that obliges students to report violations they learn about or observe

Modified honor codes involve some subset of the four elements, and predictably they are less effective than pure honor codes but better than no code at all (McCabe \& Pavela, 2000). Though the most controversial, the reporting clause seems to be the most effective (McCabe, Trevino, \& Butterfield, 2001).

\section{Cheating as a Coping Strategy in a Stressful Environment}

We need to acknowledge that students, especially millennials, are under tremendous pressure to achieve (Howe $\&$ Strauss, 2000). This pressure comes from parental expectations, the rising cost of tuition, societal emphasis on grades, and a tighter job market. In the face of such pressure, cheating might be a way for a student to keep head above water in spite of the best intentions. Research on the correlates of cheating lends support to this hypothesis. In fact, achievement motivation has a small positive effect on cheating, while external pressure to achieve high grades, perceived workload, and perceived competition all have a medium positive effect on cheating (Whitley, 1998).

\section{Cheating as Professional Development}

Unfortunately, some recent public scandals have demonstrated that people can cheat their way to the top and profit, while many others suffers as a result. Some students might make sense of events such as the Enron and other corporate and political scandals by deciding that cheating skills are essential for professional success, and that higher education is the perfect setting in which to develop and hone them. Almost twenty years ago, Moffatt (1990) warned that the university is "a place where cheating comes almost as natural as breathing, where it's an academic skill almost as important as reading, writing, and math" (p. 2). Sadly, the literature supports this speculation. Business undergraduates have long been documented as cheating at a higher rate than other students (Bowers, 1964), but recent 
research documents that even MBA students do the same (McCabe, Butterfield, \& Trevino, 2006). Ghoshal (2005) has argued that “by propagating ideologically inspired amoral theories, business schools have actively freed their students from any sense of moral responsibility" (p. 76).

\section{Cheating as a Developmental Stage}

Might cheating be just a stage that most students naturally outgrow once they become professionals and see a more direct link between actions and their consequences? During my workshops on academic integrity, several instructors invariably come forth and volunteer their "confessions of a reformed cheater." Research on the correlates of cheating lends some support to the developmental hypothesis. Students' age has a moderate negative effect on cheating, as does marital status; married students tend to cheat less. Number of hours per week employed has a small negative effect on cheating, financial support from parents has a small positive effect, and living off campus as opposed to on campus has a small negative effect (Whitley, 1998). All these variables taken together point to the fact that the more maturity, independence, and responsibility students develop, the less they cheat.

This developmental hypothesis also implies a developmental strategy: helping students reach a higher level of maturity sooner by giving them more responsibility for their own lives.

\section{Cheating as a Game}

Game theory (von Neumann \& Morgenstern, 1944) is a mathematical formalization of strategic situations among two or more players who have at their disposal a set of strategies, or moves, that they can use toward the goal of maximizing their individual payoff. Each individual move has a payoff that is dependent on the other player's move. In this vein, a student has several moves available during an exam-for example, attempt to solve the problem on his own, look over another student's test, or reach for his cheat sheet. The game is sequential in that each student move triggers the proctor's moves. For example, if the student looks over another student's test and the proctor sees him doing so, the proctor can ignore it, give a warning, or fail the student for the exam. If given a warning, the student can heed it or ignore it and try again. If the student is eventually failed for cheating, he can still do nothing or plead, cry, appeal the decision to the academic review board, and so on. Depending on the value the student associates with each possible outcome, and also 
depending on the probability the student ascribes to the proctor's moves, the student can find the optimal path through this game. The game reaches equilibrium if the players, in trying to maximize their payoff, arrive at a sequence of moves from which neither derives an advantage by deviating. The current high level of cheating, which has been fairly stable for forty years, can be interpreted as an aggregate equilibrium between students and instructors' current strategies.

The game theory approach is similar to the rational choice theory, but it has two main differences. In game theory, the instructor is also a player, with a set of strategies to use and the option of suddenly changing strategy or even affecting the payoffs. The payoffs can be modeled to incorporate a number of variables. For instance, Magnus et al. (2002) suggest that the social cost of going against the grain of the cheating culture on campus could be incorporated in the payoff function. The second difference is that game theory makes no ethical or moral claims on the situation and thus is likely closer to many students' thinking.

Despite the promise of the game-theory approach, scholars have not yet applied it to student cheating, so I have been unable to locate an empirical analysis of cheating through this theoretical lens.

\section{Implications for Educational Development}

In many institutions, educational developers lead the campus community in conversation about academic integrity. We have opportunities in several areas. First, we can push for efficient and transparent processes for our academic review boards. In time, this effort would encourage more instructors to pursue breaches of academic integrity. Second, we can give faculty more effective countermeasures to cheating. When instructors discuss cheating prevention, they often focus on decreasing the opportunities to cheat, especially in the wake of new technologies that promote cheating, such as calculators and phones that can store documents and give access to the Internet. Instead, we can remind faculty to act on the intention side, encouraging them to think of interventions to reduce students' inclination to cheat, such as educating students about the far-reaching consequences of academic dishonesty. Using the game theory approach, we can ask instructors to think about how they are increasing or decreasing the payoffs for certain courses of action with the messages they explicitly or implicitly communicate in their courses. Third, partnering with student affairs and health services professionals, we can work to equip students with better coping strategies to deal with stress, such as time management skills, holistic wellness programs, and the like. Fourth, 
we can prompt the administration to review overload policies. We know increased workload leads to more cheating, so we should be thinking about how many credits or units per semester we allow students to take. Finally, we can engage the campus community in conversations about honor codes. Apart from personality variables, which we can't control, honor codes reduce cheating more than all the situational factors. Yet their adoption has been very slow. Our signature skill set-listening actively, bringing in various constituencies, reconciling conflicting viewpoints, and gradually building consensus-can surely help here.

As we support our faculty in the scholarship of teaching and learning, we can help our colleagues document and disseminate classroom interventions that work in preventing cheating. More broadly and importantly, as we continue to promote creation of learning experiences that meaningfully engage students and call for authentic assessments, we help transform the educational system in ways that make cheating inefficient and undesirable. Undoubtedly, cheating is a daunting problem to solve, but educational development has a lot to offer and can effect significant change.

\section{REFERENCES}

Ajzen, 1. (1969). The prediction of behavior intentions in a choice situation. Journal of Experimental Psychology, 5(4), 400-416.

Aronson, E., \& Metree, D. (1968). Dishonest behavior as a function of differential levels of induced self-esteem. Journal of Personality and Social Psychology, 9(2), 121-127.

Bowers, W. J. (1964). Student dishonesty and its control in college. New York: Columbia University, Bureau of Applied Social Research.

Brown, B., \& Emmett, D. (2001). Explaining the variations in the level of academic dishonesty in studies of college students: Some new evidence. College Student Journal, 35(4), 529-538.

Burns, S., Davis, S., \& Hoshino, J. (1998). Academic dishonesty: A delineation of cross-cultural patterns. College Student Journal, 32(4), 590-596.

Carpenter, D., Harding, T., \& Finelli, C. (2006). The implications of academic dishonesty in undergraduate engineering on professional ethical behavior. Proceedings of the 2006 World Environmental and Water Resources Congress. Red Hook, NY: Curran Associates.

Cohen, J. (1988). Statistical power analysis for the behavioral sciences (2nd ed.). Hillsdale, NJ: Erlbaum.

Cornish, D., \& Clarke, R. (1986). The reasoning criminal: Rational choice perspectives on offending. New York: Springer-Verlag. 
Fletcher, J. (1966). Situational ethics. Philadelphia: Westminster Press.

Ghoshal, S. (2005). Bad management theories are destroying good management practice. Academy of Management Learning and Education, 4(1), 75-91.

Higbee, J., \& Thomas, P. (2002). Student and faculty perceptions of behaviors that constitute cheating. NASPA Journal, 40(1), 39-52.

Howe, N., \& Strauss, W. (2000). Millennials rising: The next great generation. New York: Vintage.

Magnus, J., Polterovich, V., Danilov, D., \& Savvateev, A. (2002). Tolerance of cheating: An analysis across countries. Journal of Economic Education, $33(2), 125-135$.

McCabe, D., Butterfield, K., \& Trevino, L. (2006). Academic dishonesty in graduate business programs: Prevalence, causes, and proposed action. Academy of Management Learning and Education, 5(3), 294-305.

McCabe, D., \& Pavela, G. (2000). Some good news about academic integrity. Change, 32(5), 32-38.

McCabe, D., \& Trevino, L. (1993). Academic dishonesty: Honor codes and other contextual influences. Journal of Higher Education, 64, 522-538.

McCabe, D., Trevino, L., \& Butterfield, K. (1999). Academic integrity in honor code and non-honor code environments: A qualitative investigation. Journal of Higher Education, 70(2), 211-234.

McCabe, D., Trevino, L., \& Butterfield, K. (2001). Dishonesty in academic environments: The influence of peer reporting requirements. Journal of Higher Education, 72(1), 2-45.

Melendez, B. (1985). Honor code study. Cambridge, MA: Harvard University Press.

Moffatt, M. (1990). Undergraduate cheating. Unpublished manuscript, Rutgers University, New Brunswick, New Jersey. (ERIC Document Reproduction Service No. ED334921)

Nonis, S., \& Swift, C. (2001). An examination of the relationship between academic dishonesty and workplace dishonesty: A multicampus investigation. Journal of Education for Business, 77(2), 69-77.

Rutgers University. (2009). 198:415 compilers, spring 2009: Academic integrity. Retrieved March 2, 2009, from http://remus.rutgers.edu/cs415/ academicInteg.html

Schneider, A. (1999, January 22). Why professors don't do more to stop students who cheat. Chronicle of Higher Education, pp. A8-A10.

Stern, E., \& Havlicek, L. (1986). Academic misconduct: Results of faculty and undergraduate student surveys. Journal of Allied Health, 15(2), 129-142.

Storch, J., Storch, E., \& Clark, P. (2002). Academic dishonesty and neutralization theory: A comparison of intercollegiate athletes and nonathletes. Journal of College Student Development, 43(6), 921-930. 
Sykes, G. M., \& Matza, D. (1957). Techniques of neutralization: A theory of delinquency. American Sociological Review, 22(6), 664-670.

von Neumann, J., \& Morgenstern, O. (1944). Theory of games and economic behavior. Princeton, NJ: Princeton University Press.

Ward, D. (1986). Self-esteem and dishonest behavior revisited. Journal of Social Psychology, 126(6), 709-713.

Whitley, B. (1998). Factors associated with cheating among college students:

A review. Research in Higher Education, 39(3), 235-274.

Wilhoit, S. (1994). Helping students avoid plagiarism. College Teaching, 42(4), 161-164.

Zimring, F. E., \& Hawkins, G. J. (1973). Deterrence: The legal threat in crime control. Chicago: University of Chicago Press. 